\title{
GvHH Patogenezi ve Biyolojisi
}

\section{Pathogenesis and Biology of Graft-Versus-Host Disease}

\author{
Demet Kıvanç $^{1}\left(\mathbb{D}\right.$, Fatma Savran Oğuz $^{1}$ (i) \\ ${ }^{1}$ İstanbul Üniversitesi, İstanbul Tıp Fakültesi, Tıbbi Biyoloji Bilim Dalı, İstanbul, Türkiye
}

ORCID ID: D.K. 0000-0002-2451-5709; F.S.O. 0000-0002-6018-8936

Atff/Citation: Kivanc D, Savran Oguz F. GvHH Patogenezi ve Biyolojisi. Çocuk Dergisi - Journal of Child 2020;20(3):115-119. https://doi.org/10.26650/jchild.2020.3.780358

öz

Graft versus host hastalığı (GvHH) genellikle hematopoetik kök hücre nakli (HKHN) sonrası gelişen ve nakil işleminin başarısını etkileyen önemli bir komplikasyondur. GvHH'nin iyi yönetilmesi, önlenmesi ve tedavi stratejilerinin geliştirilebilmesi için patogenezi, risk faktörleri, prognozu ve biyobelirteçlerinin tespit edilmesi önemlidir. Bu derlemede GvHH biyolojisinde etkili olan faktörlerden klasik ve klasik olmayan insan lökosit antijenleri (HLA) genleri, minör HLA antijenleri, sitokinler, kemokinler ve kostimülatör moleküller ile ilgili literatürde yer alan güncel çalışmalar sunulmuştur.

Anahtar Kelimeler: Graft versus host hastalığ, hematopoetik kök hücre nakli, insan lökosit antijenleri

\section{GiRiş}

\section{Graft Versus Host Hastalığı}

Graft versus host hastalığı (GvHH); enflamasyonu destekleyen bir ortamda verici lenfositlerinin yabancı antijenlerle etkileşime girdiği, normal enflamasyonun abartılı ve istenmeyen bir şekli olarak tanımlanabilir (1). Hematopoetik kök hücre nakli (HKHN) sonrası morbidite ve mortalitenin en önemli nedenlerinden biri olması dolayısıyla çok iyi yönetilmesi gereken önemli bir komplikasyondur (2,3). Genellikle allojeneik hematopoetik kök hücre nakli sonrası ortaya çıkmakta olup nadir olarak kan ve kan ürünleri transfüzyonu (4), solid organ nakli (5) veya otolog hematopoetik kök hücre nakli (6) sonrası da gelişebilir. Yapılan çalışmalarda HKHN sonrası GvHH insidansının \%40 ila \%60’a kadar yükselebildiği ve mortalite oranının \%15'e yaklaştı̆ı bildirilmiştir (7).

\section{Graft versus Host Hastalığının Sınıflandırılması}

GvHH'nin akut ve kronik olmak üzere 2 formu tanımlanmıştr. Genel olarak HKHN sonrası ilk 100 gün içinde ortaya çıkan

\section{ABSTRACT}

Graft-versus-host disease (GvHD) is an important complication that usually develops after hematopoietic stem cell transplantation and affects the success of the transplant. It is important to identify the pathogenesis, risk factors, prognosis, and biomarkers for the management and prevention of GvHD, as welll as the development of treatment strategies for GvHD. This review presents current literature studies on factors that affect GvHD biology, including classical and nonclassical human leukocyte antigen (HLA) genes, minor HLA antigens, cytokines, chemokines, and costimulatory molecules.

Keywords: Graft-versus-host disease, hematopoietic stem cell transplantation, human leukocyte antigens

GvHH akut form olarak tanımlanırken, 100 günden sonra gelişen GvHH kronik form olarak adlandırılmaktaydı (8). Fakat GvHH profilaksisinde kullanılan immünsüpresif ilaçlar, kök hücrelerin işlenmesinde kullanılan farklı yöntemler ve miyeloablatif olmayan hazırlık rejimlerinin kullanımı gibi etkenlere bağlı olarak akut ve kronik GvHH arasındaki süre eşiğinin ortadan kalktığı gözlenmiş ve bu durum akut/kronik GvHH ayrımında belirli bir süre yerine klinik bulguların kullanımında artışa neden olmuştur (9). Ulusal Sağlık Enstitüleri 2005 ve 2014 yıllarında akut ve kronik GvHH ayrımı ile ilgili yeni uzlaşı kriterleri yayınlamıştır. Bu kriterlere göre GvHH 4 alt sınıfa ayrılır $(10,11)$;

Klasik akut GvHH (aGvHH): Akut GvHH (aGvHH)'nin klinik özellikleri görülür ve allojenik HKHN veya verici lenfosit infüzyonundan (DLI) itibaren 100 gün içinde ortaya çıkar. Kronik GvHH'nin $(\mathrm{kGvHH})$ tanı ve ayırt edici özellikleri yoktur.

Kalıcı ve / veya tekrarlayan geç başlangıçlı aGvHH: Allojenik HKHN veya DLI'dan 100 gün sonra ortaya çıkar. Klasik aGvHH özelliklerini gösterir. Kronik GvHH'nin tanısal belirtileri yoktur.

Sorumlu Yazar/Corresponding Author: Demet Kıvanç E-mail: demet.kivanc@istanbul.edu.tr

Başvuru/Submitted: 14.08.2020 • Revizyon Talebi/Revision Requested: 02.11.2020 • Son Revizyon/Last Revision Received: 02.11 .2020 • Kabul/Accepted: 03.11.2020 
Klasik kGvHH: HKHN'den sonra herhangi bir zamanda ortaya çıkar. Akut GvHH bulguları olmaksızın kGVHH'nin tanı ve ayırt edici özelliklerini gösterir.

Overlap sendromu: Hem kGvHH hem de aGvHH'nin özellikleri görülebilir.

\section{Graft versus Host Hastalığı Patogenezi}

Akut GvHH gelişimi başlıca 3 aşamada gerçekleşir (Şekil 1). İlk aşama hastaya uygulanan hazırlık rejiminin neden olduğu doku hasarının konağa ait antijen sunan hücreleri (ASH) aktive etmesidir. Hematopoetik kök hücrelerin infüzyonundan önce hastalara uygulanan hazırlık rejimi protokolünde yer alan kemoterapi ve radyoterapiler doku hasarına neden olurlar. Gelişen doku hasarı immün yanıtın lipopolisakkaritler (LPS), ürik asit ve adenozin trifosfat yolu reseptörlerinin metabolitleri gibi pek çok ekzojen moleküler aktivatörleri ve tümör nekrozis faktör (TNF) alfa, interlökin (IL) 6, IL-1 gibi endojen moleküler aktivatörlerinin salınımını tetikler $(12,13)$. Salınan LPS bir yandan mononükleer fagositleri aktive ederek GvHH yanıtını güçlendiren bir döngüyü tetiklerken $(14,15)$ bir yandan da bu ekzojen ve endojen moleküller büyük doku uyum kompleksi (major histocompatibility complex, MHC) antijenleri ve adhezyon moleküllerinin ekspresyonunun artmasına neden olarak konakçıya ait alloantijenlerin verici T hücreleri tarafindan daha fazla tanınmasına ve T hücrelerinin uyarımına yol açar (14).

GvHH gelişiminin ikinci aşamasında verici T hücreleri HKHN'nin erken evrelerinde konağa ait ASH ile (doğrudan antijen sunumu) ilerleyen zamanlarda ise vericiye ait ASH'ler ile (dolaylı antijen sunumu) etkileşime girerek aktive olur. Bu aktivasyon yardımcı T hücreler (Th), sitotoksik T hücreler (CTL) ve bunların Th1, Th2, Th17 gibi alt gruplarının ekspansiyonuna yol açan kostimülatör sinyaller sağlar (16). Son aşamada ise sitotoksik efektör T hücreler kemokinler ve reseptör etkileşimleri yolu ile cilt, gastrointestinal sistem, karaciğer, akciğer gibi hedef organlara dağılır ve buralarda doku hasarına neden olurlar $(14,15)$. Bu aşamada, hem doğal hem de adaptif immün sistem hücreleri, $T$ hücresi kaynaklı inflamasyonun şiddetini arttırmak için beraber çalışırlar. Doğal öldürücü (NK) hücreler ve CTL'ler Fas/Fas ligand (FasL) ve perforin/granzim yolunu kullanarak hedef hücreleri lizise uğratır. Ayrıca, enflamatuvar sitokinler CTL'lerle sinerjiye girerek daha fazla doku hasarı ve hedef organda fonksiyon bozukluğuna neden olurlar. Uygulanan hazırlık rejimi sırasında salgılanan LPS gibi mikrobiyal ürünler de, hasarlı bağırsak mukozasından ve deriden sızarak sitokin firtınasının çoğalıp yayılmasına yol açan enflamatuvar sitokinleri salmaları yönünde monositler/makrofajlar gibi mononükleer hücreleri uyarır. Bu durum çoğunlukla gastrointestinal alanda yer alan epitel hücrelerinin tahrip olmasına yol açar $(14,15)$.

\section{Kronik Graft versus Host Hastalığı Patogenezi}

Akut GvHH, kGvHH'nin önemli bir risk faktörüdür. Timus, kemik iliği nişi ve dalak gibi immün sistem organları ile immün sistem hücreleri aGvHH'nin birincil hedefleridir. Timus yıkımı ve sonucunda verici T hücrelerinin timus tarafindan yetersiz eliminasyonu, kGvHH ile ilişkili allo- ve otoimmüniteye neden olan başlıca faktörlerdir (17). Ayrıca kemik iliğindeki B hücresi nişinin hasar görmesi nedeniyle, B hücresi gelişimi bozulur. Bu durum oto- ve alloantikorlar üreten $B$ hücrelerinin yetersiz eliminasyonuna yol açar ve kanda kGvHH'nin bir belirteci olan $B$ hücre aktive edici faktör (B-cell-activating factor, BAFF) seviyeleri yükselir (18). Kronik GvHH gelişimi 3 aşamada meydana gelir (Şekil 2). Illk aşamada sitotoksik doku hasarı, enfeksiyonlar ve aGvHH kaynaklı meydana gelen hasar hem doğal immün sistem hücrelerinin hem de fibroblastlar ve endotelyal hücrelerin aktive olmasını sağlar. İkinci aşama adaptif immün sistemin aşırı duyarlılığı ve immün regülatörlerin azalması ile karakterizedir. Bu aşamada konaktaki yabancı MHC hücrelerine karşı Th1, Th2, Th17 gibi hücrelerde artı̧a, regülatör T hücrelerinde (Treg) azaIışa neden olan bir immün yanıt gelişir. Kronik GvHH gelişiminin son aşamasında ise fibroblast aktivasyonuna yol açan TNF- $\beta$ ve trombosit kaynaklı büyüme faktörü (platelet-derived growth factor, PDGF) üreten aktive makrofajların desteklediği anormal doku onarımı görülür $(19,20)$.

\section{KLINIK VE ARAŞTIRMA ETKILERI}

\section{Pediatri Hastalarında GvHH Gelişiminde Risk Faktörleri}

Her yaştan hastada akut GvHH için en önemli risk faktörü, verici ve alıcı arasındaki HLA uyuşmazlığıdır. Pediyatrik hastalarda diğer potansiyel risk faktörleri arasında alıcı yaşı $(21,22)$, tanı, nakil öncesi gastrointestinal yolun hasarlı olması, akraba dışı bir vericinin kullanımı, verici yaşının büyük olması (>8), erkek hasta için multipar kadın verici kullanımı, kök hücre kaynağı, yüksek CD34 pozitif hücre dozu ve hazırlık rejiminde tüm vücut ışınlaması kullanımı yer almaktadır $(23,24)$.

MHC gen bölgesi 6. kromozomun kısa kolunda lokalize olup 3 bölgeye ayrılır. (Şekil 3). I. bölge klasik la ve klasik olmayan Ib moleküllerini, II. bölge klasik Ila ve klasik olmayan Ilb moleküllerini, III. bölge ise kompleman ve TNF ile ilişkili molekülleri kodlayan genlerden oluşur. HLA-A, HLA-B ve HLA-C klasik HLA sınıf I üyeleri iken HLA-E, HLA-F, HLA-G, MICA ve MICB klasik olmayan HLA sınıf I üyeleridir (25). Klasik olmayan HLA sınıf I molekülleri sınırlı ekspresyona sahiptir

\section{HLA Sınıf I ve sınıf II Genleri ve GvHH}

MHC gen bölgesi 6. kromozomun kısa kolunda yer alır ve HLA genlerinin yanı sıra bir kısmı immün yanıtta yer alan 391 farklı geni de içerir (27). HLA sınıf I molekülleri pek çok hücrede eksprese edilir ve hücre içi peptidleri bağlayarak CTL'lerin reseptörlerine sunar. Bu peptitlerin CTL hücreleri tarafindan yabancı olarak algılanması durumunda sitotoksik bir yanıt başlatılır. HLA sınıf II molekülleri ise antijen sunan hücrelerde eksprese olur ve hücre dışı peptitleri bağlayarak Th hücrelerinin reseptörlerine sunar. Böylece aktive olan Th hücreleri çoğalır ve yabancı olarak algılanan antijene karşı antikor üreten $\mathrm{B}$ hücrelerin uyarılmasını sağlayan sinyallerin oluşumu tetiklenir (28). HLA bölgesi, insan genomundaki en polimorfik bölgedir (29) ve HLA uyumsuzluğu GvHH gelişimi için en önemli risk faktörü olarak tanımlanmıştır. HLA-A,-B,-C klasik sınıf I HLA molekülleri iken HLA-DRB1,DQB1,-DQA1 ve HLA-DPB1 klasik sınıf II HLA molekülleridir. Lee SJ ve arkadaşlarının gerçekleştirdiği bir çalışmada 3856 hasta ve verici çifti değerlendirilmiş ve HLA-A,-B,-C,-DRB1 tam uyumlu hasta-verici çiftlerinde 1 alel/antijen uyumsuz olanlara göre 
daha iyi genel sağ kalım, daha düşük transplant ilişkili mortalite ve daha düşük aGvHH görüldüğü, tek başına HLA-DQB1 uyumsuzluğunun ise nakil sonucunu önemli ölçüde etkilemediği bildirilmiştir. İlgili çalışmada nüks, kGvHH oranı ve engraftman süresi açısından ise iki grup arasında herhangi bir fark saptanmamıştır (30). Ayrıca literatürde yer alan bazı çalışmalarda non-permisif (tolere edilemeyen) HLA-DPB1 uyumsuzluğu da aGvHH ile ilişkili bulunmuştur (31-33).

Minör HLA Antijenleri ve GvHH iliş̧kisi: Minör histo-uyumluluk antijenleri, hücre yüzeyi üzerinde sınıf I veya sınıf II MHC molekülleri ile ilişkili olarak bulunan küçük peptitlerdir. İmmün sistemin öz tanımasında etkilidirler. Çoğu minör H antijeni epitelyal dokularda dahil olmak üzere birçok yerde eksprese olur ve bu minör $\mathrm{H}$ antijenlerinin HKHN'yi takiben verici T hücreleri tarafindan tanınması GvHH ve Graft versus lösemi (GvL)'ye neden olabilir (34). HLA tam uyumlu allojenik nakillerde tek antijen uyumsuzlukları immünoreaktif $\mathrm{T}$ hücreleri tarafindan tespit edilebilir ve GvHH gelişime neden olabilir (35).

Yapılan çalışmalarda minör $\mathrm{H}$ antijeni HA-8 veya UGT2B17 uyumsuzluğunun, GvHH riskini arttırdığı tespit edilmiştir (36, 37). Martin ve arkadaşları çalışmalarında HLA tam uyumlu kardeş verici nakillerinde, minör histo-uyumluluk antijen dengesizliğinde bir artışın şiddetli (derece 3-4) ve evre 2-4 bağırsak GvHH'sini arttırdığını tespit etmiştir (38).

\section{Sitokinler, Kemokinler, Kostimülatör moleküller ve GvHH ilişkisi}

Sitokinler, GvHH patogenezinde rol oynayan önemli efektör ve düzenleyici moleküllerdir. Aktive olan immün sistem hücreleri tarafindan salınan proenflamatuvar sitokinler bir 'sitokin firtnası' oluşturarak GvHH'nin hızıı bir şekilde başlamasına yol açar (39). GvHH'nin ortaya çıkışı ve şiddeti Treg, Th1, Th2 ve Th17 hücreleri gibi farklı fenotiplere olgunlaşan ve farklılaşan saf $T$ hücreleri tarafindan belirlenir. Bu farklılaşma, transkripsiyon faktörlerini aktive eden ve bazı fenotiplerin üstünlüğünü sağlayan lokal sitokinlerin varlığı ile ilişkilidir (40). Th1 hücreleri, IL-2, IL-10, interferon-gama (IFN-y), TNF-a ve TNF-y gibi sitokinleri salgılar. Th2 hücreleri IL-3, IL-4, IL-5, IL-10, IL-13, IL-17E ve IL-31 gibi sitokinleri salgılar. Th17'nin temel olarak IL-17'yi salgıladığı bilinmektedir (41). GvHH'de verici naif CD4+ T hücreleri, konağa ait $\mathrm{ASH}^{\prime}$ ler tarafindan sunulan allo-antijenleri tanır ve ortamda mevcut sitokin profiline bağlı olarak Th1, Th2 veya Th17 hücrelerine farklılaşır (42). Yi T. ve arkadaşları çalışmalarında ortamda IFN-y yokluğunda, Th hücrelerinin Th2 ve Th17 alt gruplarına farklılaşarak akciğer ve deride hasara neden olduğunu, hem IL-4 hem IFN-y yokluğunda, Th17 hücrelerinin baskın alt grup haline gelip deride doku hasarına yol açthğını, hem IFN-y hem de IL-17 yokluğunda ise Th2 alt grubunun baskın hale gelip $\mathrm{GvHH}$ hastalarında idiyopatik pnömoniye neden olduğunu tespit ettiklerini bildirmişlerdir (43). Ayrıca, Th hücrelerinin ortamda IL-12 sitokini varlığında Th1 fenotipine farklılaştı̆̆ ve IFN-y ile IL-2 sitokinlerinin salınmasına neden olduğu tespit edilmiştir (40). Bununla birlikte yapılan çalışmalarda sitokinlerin NK hücrelerinin modülasyonunda da potansiyel bir rol oynadığı gösterilmiştir. Huber CM. ve arkadaşlarının çalışmasında IL-12, IL-15 ve IL-18 ile aktive edilen NK hücrelerinin adoptif transferinin,
HLA uyumsuz nakil gerçekleştirilen bir fare modelinde GvHH'yi baskıladığı gösterilmiştir (43).

Akut GvHH'de CD28, TNF süper aile reseptörleri (CD40LG, OX40, 4-1BB), indüklenebilir T hücre kostimulatör sistemi (ICOS) gibi pozitif regülatörler (44) ve CTLA-4 ve PD-1 gibi negatif regülatörleri içeren çoklu kostimülatör yolların rolü de araştırılmıştır (45). Yapılan çalışmalarda kostimülatuvar moleküllerin blokajının GvHH'yi azaltabilirken, immün kontrol noktası moleküllerinin blokajının GvHH'yi arttırabileceği gösterilmiştir $(46,47)$.

\section{SONUÇ}

Günümüzde GvHH, halen HKHN sonrası ortaya çıkan en önemli komplikasyonlardan biri olmaya devam etmektedir. GvHH'nin doğru yönetilmesi HKHN sonrası morbidite ve mortalite oranlarının azaltılması açısından çok önemlidir. Bu bağlamda GvHH'nin biyolojisi, risk faktörleri, prognozu, biyobelirteçlerinin iyi anlaşılması ve önleme stratejileri ile tedavi yöntemlerinin ortaya konulması yönünde daha pek çok çalışmaya ihtiyaç vardır.

Hakem Değerlendirmesi: Dış bağımsız.

Yazar Katkıları: Çalışma Konsepti/Tasarım- D.K., F.S.O.; Veri ToplamaD.K.; Veri Analizi/Yorumlama- D.K., F.S.O.; Yazı Taslağı- D.K.; İçeriğin Eleştirel İncelemesi- D.K., F.S.O.; Son Onay ve Sorumluluk- D.K., F.S.O.; Süpervizyon- F.S.O.

Çıkar Çatışması: Yazarlar çıkar çatışması beyan etmemişlerdir.

Finansal Destek: Yazarlar finansal destek beyan etmemişlerdir.

Peer Review: Externally peer-reviewed.

Author Contributions: Conception/Design of Study- D.K., F.S.O.; Data Acquisition- D.K.; Data Analysis/Interpretation- D.K., F.S.O.; Drafting Manuscript- D.K.; Critical Revision of Manuscript- D.K., F.S.O.; Final Approval and Accountability- D.K., F.S.O.; Supervision- F.S.O.

Conflict of Interest: Authors declared no conflict of interest.

Financial Disclosure: Authors declared no financial support.

\section{KAYNAKLAR/REFERENCES}

1. Ferrara JL, Reddy P. Pathophysiology of graft versus-host disease. Semin Hematol 2006;43(1):3-10.

2. Penack $O$, Marchetti $M$, Ruutu T, Aljurf M, Bacigalupo A, Bonifazi $F$, et al. Prophylaxis and management of graft versus host disease after stem-cell transplantation for haematological malignancies: updated consensus recommendations of the European Society for Blood and Marrow Transplantation. Lancet Haematol 2020 Feb;7(2):e157-e167.

3. Carpenter PA, MacMillan ML. Management of acute graft-versus-host disease in children. Pediatr Clin North Am 2010 Feb;57(1):273-95.

4. Patel KK, Patel AK, Ranjan RR, Shah AP. Transfusion associated graft versus host disease following whole blood transfusion from an unrelated donor in an Immunocompetent patient. Indian J Hematol Blood Transfus 2010 Sep;26(3):92-5. 
5. Saffo S, Peng C, Kibbi N, Patel N, Robert ME, Adekolu E, et al. Graftversus-host disease after pancreatic transplantation. ACG Case Rep J 2019 Sep 12;6(9):e00214.

6. Batra A, Cottler-Fox M, Harville T, Rhodes-Clark BS, Makhoul I, Nakagawa M. Autologous graft versus host disease: An emerging complication in patients with multiple myeloma Bone Marrow Res 2014;2014:891427.

7. Jagasia M, Arora M, Flowers ME, Chao NJ, McCarthy PL, Cutler CS, et al. Risk factors for acute GVHD and survival after hematopoietic cell transplantation. Blood 2012 Jan 5;119(1):296-307.

8. Billingham RE. The biology of graft-versus-host reactions. Harvey Lectures 1966-67;62:21-78.

9. Mielcarek M, Martin PJ, Leisenring W, Flowers ME, Maloney DG, Sandmaier BM, et al. Graft-versus-host disease after nonmyeloablative versus conventional hematopoietic stem cell transplantation. Blood 2003 Jul 15;102(2):756-62.

10. Filipovich AH, Weisdorf D, Pavletic S, Socie G, Wingard JR, Lee SJ, et al. National Institutes of Health consensus development project on criteria for clinical trials in chronic graft-versus-host disease: I. Diagnosis and staging working group report. Biol Blood Marrow Transplant 2005 Dec;11(12):945-56.

11. Pavletic SZ, Vogelsang GB, Lee SJ. 2014 National Institutes of Health consensus development project on criteria for clinical trials in chronic graft-versus-host disease: Preface to the series. Biol Blood MarrowTranspl 2015 Mar;21(3):387-8.

12. Apostolova P, Zeiser R. The role of danger signals and ectonucleotidases in acute graft-versus- host disease. Hum Immunol 2016 Nov;77(11):1037-47.

13. Zeiser R, Penack O, Holler E, Idzko M. Danger signals activating innate immunity in graft-versus-host disease. J Mol Med(Berl) 2011 Sep;89(9):833-45.

14. Reddy P. Pathopysiology of acute graft versus host disease. Hematol Oncol 2003 Dec:21(4):149-61.

15. Sung AD, Chao NJ. Acute graft-versus-host disease: Are we close to bringing the bench to the bedside? Best Pract Res Clin Haematol 2013 Sep;26(3):285-92.

16. Yu Y, Wang D, Liu C, Kaosaard K, Semple K, Anasetti C, et al. Prevention of GVHD while sparing GVL effect by targeting Th1 and Th17 transcription factor T-bet and RORyt in mice. Blood 2011 Nov 3;118(18):5011-20.

17. Socié G, Ritz J. Current issues in chronic graft-versus-host disease. Blood 2014 Jul 17;124(3):374-84.

18. Sarantopoulos S, Ritz J. Aberrant B-cell homeostasis in chronic GVHD. Blood 2015 Mar 12;125(11):1703-7.

19. Zeiser R, Blazar BR. Pathophysiology of chronic graft versus host disease and therapeutic targets. N Engl J Med 2017 Dec 28;377(26):2565-2579.

20. Ghimire S, Weber D, Mavin E, Wang, XN, Dickinson, AM, Holler, E. Pathophysiology of GVHD and other HSCT-related major complications. Front Immunol 2017 Mar 20;8:79.

21. Qayed M, Wang T, Hemmer MT, Spellman S, Arora M, Couriel $D$, et al. Influence of age on acute and chronic GVHD in children undergoing HLA-identical sibling bone marrow transplantation for acute leukemia: Implications for prophylaxis. Biol Blood MarrowTransplant 2018 Mar;24(3):521-8.

22. Vignon $M$, Andreoli $A$, Dhédin $N$, Lebgline $E$, Masson $E$, Robin $M$, et al. Graft-versus-host disease in adolescents and young adults (15-24 years old) after allogeneic hematopoietic stem cell transplantation for acute leukemia in first complete remission. J Adolesc Young Adult Oncol 2017 Jun;6(2):299-306.
23. Carlberg V, Simons E, Delano S, Huang JT. Pediatric GraftVersus-Host Diease In: Cotliar JA, eds. Atlas of Graft-Versus-Host Diease: Approaches to Diagnosis and Treatment. Cham, 1st ed. Switzerland: Springer International Publishing AG, 2017:105-23.

24. Gatza E, Reddy P, Choi SW. Prevention and treatment of acute graftversus-host disease in children, adolescents, and young adults. Biol Blood Marrow Transplant 2020 May;26(5):e101-e112.

25. Hosseini E, Schwarer AP, Ghasemzadeh M. The impact of HLA-E polymorphisms in graft-versus-host disease following HLA-E matched allogeneic hematopoietic stem cell transplantation. Iran J Allergy Asthma Immunol 2012;11(1):15-21.

26. Hosseini E, Schwarer AP, Ghasemzadeh M. Do human leukocyte antigen $\mathrm{E}$ polymorphisms influence graft-versus-leukemia after allogeneic hematopoietic stem cell transplantation? Exp Hematol 2015 Mar;43(3):149-57.

27. The IMGT/HLA Database; http://www.ebi.ac.uk/imgt/hla/stats. html Erişim tarihi: 27.03.2014

28. Meyer D, Aguriar VRC, Bitarello BD, Brandt DYC, Nunes K. A genomic perspective on HLA evolution. Immunogenetics 2018 Jan;70(1):5-27.

29. Edgerly $\mathrm{CH}$, Weimer ET. The Past, present, and future of HLA typing in transplantation. Methods Mol Biol 2018;1802:1-10.

30. Lee SJ, Klein J, Haagenson M, Baxter-Lowe LA, Confer DL, Eapen M, et al. High-resolution donor recipient HLA matching contributest othe success of unrelated donor marrow transplantation. Blood 2007 Dec 15;110(13):4576-83.

31. Touzeau C, Gagne K, Sebille V, Herry P, Chevallier P, Follea G, et al. Investigation of the impact of HLA-DPB1 matching status in 10/10 HLA matched unrelated hematopoietic stem cell transplantation: results of a French single center study. Hum Immunol 2012 Jul;73(7):711-4.

32. Crocchiolo R, Zino E, Vago L, Oneto R, Bruno B, Pollichieni S, et al. Nonpermissive HLA-DPB1 disparity is a significant independent risk factor for mortality after unrelated hematopoietic stem cell transplantation. Blood 2009 Aug 13;114(7):1437-44.

33. Rene C, Lozano C, Eliaou JF. Expression of classical HLA class I molecules: regulation and clinical impacts: Julia Bodmer award review 2015. HLA 2016 May;87(5):338-49.

34. Summers C, Sheth VS, Bleakley M. Minor histocompatibility antigen-specific T cells. Front Pediatr 2020 Jun3;8:284.

35. Roy DC, Perreault C. Major vs minor histocompatibility antigens. Blood 2017 Feb 9;129(6):664-6.

36. Akatsuka Y, Warren EH, Gooley TA, Brickner AG, Lin MT, Hansen $J A$, et al. Disparity for a newly identified minor histocompatibility antigen, HA-8, correlates with acute graft-versus-host disease after haematopoietic stem cell transplantation from an HLA-identical sibling. Br J Haematol 2003 Nov;123(4):671-5.

37. McCarroll SA, Bradner JE, Turpeinen H, Volin L, Martin PJ, Chilewski $S D$, et al. Donor-recipient mismatch for common gene deletion polymorphisms in graft-versus-host disease. Nat Genet 2009 Dec;41(12):1341-4.

38. Martin PJ, Levine DM, Storer BE, Warren EH, Zheng X, Nelson SC et al. Genome-wide minor histocompatibility matching as related to the risk of graft-versus-host disease. Blood 2017 Feb 9;129(6):791-8.

39. Mohty M, Blaise D, Faucher C, Vey N, Bouabdallah R, Stoppa $A M$, et al. Inflammatory cytokines and acute graft-versus-host disease after reduced-intensity conditioning allogeneic stem cell transplantation. Blood 2005 Dec 15;106(13):4407-11.

40. Henden AS, Hill GR. Cytokines in graft-versus-host disease. J Immunol 2015 May 15;194(10):4604-12. 
41. Kumar S, Mohammadpour H, Cao X. Targeting cytokines in GVHD therapy. J Immunol Res Ther 2017;2(1):90-9.

42. Yi T, Chen Y, Wang L, Du G, Huang D, Zhao D, et al. Reciprocal differentiation and tissue- specific pathogenesis of Th1, Th2, and Th17 cells in graft-versus-host disease. Blood 2009 Oct 1;114(14):3101-12.

43. Hüber CM, Doisne JM, Colucci F. IL-12/15/18-preactivated NK cells suppress GVHD in a mouse model of mismatched hematopoietic cell transplantation. Eur J Immunol 2015 Jun;45(6):1727-35.

44. Taylor PA, Panoskaltsis-Mortari A, Freeman GJ, Sharpe AH, Noelle RJ, Rudensky AY, et al. Targeting of inducible costimulator (ICOS) expressed on alloreactive T cells down-regulates graft-versus-host disease (GVHD) and facilitates engraftment of allogeneic bone marrow (BM). Blood 2005 Apr 15;105(8):3372-80.
45. Zeiser R, Blazar BR. Acute graft versus host disease-biologic process, prevention and therapy. N Engl J Med 2017 Nov 30;377(22):216779.

46. Ijaz A, Khan AY, Malik SU, Faridi W, Fraz MA, Usman M, et al. Significant risk of graft-versus-host disease with exposure to checkpoint inhibitors before and after allogeneic transplantation. Biol Blood Marrow Transplant 2019 Jan;25(1):94-9.

47. Haverkos BM, Abbott D, Hamadani M, Armand P, Flowers ME, Merryman E, et al. PD-1 blockade for relapsed lymphoma postallogeneic hematopoietic cell transplant: high response rate but frequent GVHD. Blood 2017 Jul 13;130(2):221-8. 